\title{
The role of temperature and velocity on deformation and wear mechanisms in fundamental abrasive contacts up to $800^{\circ} \mathrm{C}$
}

\author{
H. Rojacz \& M. Varga \\ $A C^{2} T$ research $\mathrm{GmbH}$, Austria
}

\begin{abstract}
Abrasion of metallic materials, especially at elevated temperatures, is a complex process with many influencing factors which ultimately lead to material loss in many applications. This work focus on the investigation of deformation and wear mechanisms present during a single abrasive event. Thereto the scratch behaviour of different steels were studied under variation of different parameters like temperature, which influences microstructural changes and a concomitant hardness drop, and velocity, which strongly affects the hardening mechanisms within the deformed areas. Both parameters influence the resistance against a penetrating abrasive. Therefore a high temperature scratch test (HT-ST) was developed, which enables scratch testing from 1-100 N and temperatures up to $1000^{\circ} \mathrm{C}$. Within this study a diamond frustum with a tip radius of $200 \mu \mathrm{m}$ was chosen as indenter. Scratch tests were performed at room temperature, $500^{\circ} \mathrm{C}$ and $800^{\circ} \mathrm{C}$. Normal load was kept constant at $50 \mathrm{~N}$ and sliding velocities were set between $1 \mathrm{~mm} / \mathrm{s}$ and $1 \mathrm{~mm} / \mathrm{min}$. Three steels were chosen for investigation: (i) a ferritic-pearlitic steel, (ii) a ferritic steel with chromium carbides and (iii) an austenitic steel. For the determination of wear mechanisms light microscopy and 3D-confocal white light microscopy were used. High resolution scanning electron microscopy, including electron backscatter diffraction (EBSD) measurements, were performed on cross sections, revealing different deformation mechanisms and surface hardening effects. In the EBSD-analyses hardening effects were pointed out, using orientation mapping with inverse pole figures and grain boundary maps in deformed and initial structures. Results indicate a high influence of both temperature and velocity on the scratch behaviour of materials.

Keywords: steel, abrasion, scratch test, high temperature wear, deformation, tribology.
\end{abstract}




\section{Introduction}

Wear of metallic materials, especially at elevated temperatures, is a complex process with many influencing parameters. It is a crucial factor in decreasing the lifetime of core components in many industrial applications such as mining and heavy industry $[1,2]$. To decrease downtime and maintenance costs it is of great scientific and industrial interest to understand abrasive contacts. A hightemperature scratch test (HT-ST) [2] was developed at the Austrian Centre of Competence for Tribology $\left(\mathrm{AC}^{2} \mathrm{~T}\right)$ to examine influencing parameters on the wear behaviour of abrasive contacts up to $1000^{\circ} \mathrm{C}$.

As reported in different studies [2,3] four different physical interactions between abrasive particles and the base material can occur: (1) micro ploughing: a purely plastic deformation with no, or nearly no wear loss in ductile materials; (2) micro cutting: materials removal due top local stresses exceeding the cohesive strength of materials within ductile materials; (3) micro cracking: highly concentrated stresses are imposed by abrasive particles, mostly at brittle materials, causing wear debris due to crack formation and propagation; (4) micro fatigue: cyclic tribological surface damage with different abrasion mechanisms occurring. Due to the lack of knowledge on the influence of temperature and scratching velocity in abrasive contacts on these mechanisms, this study was performed. Increasing temperature leads to microstructural changes resulting in a hardness decrease $[4,5]$. Changes of the mechanical properties can be beneficial as well - wear can be accelerated due to a hardness drop, but can also be reduced by the formation of mechanically mixed layers, which is known in abrasive environments especially at high temperatures [5]. Strain hardening can be present, where the deformation of materials induces hardened microstructures [6]. These hardening effects can reduce wear by increasing material's hardness up to $25 \%$ [7-9].

The aim of this study is to investigate the influence of temperature and velocity on the wear behaviour of abrasive contacts using different steels. The influence of different microstructures on the abrasion resistance, their strain hardening behaviour and their hardening mechanisms should be pointed out using analytic techniques, such as optical and scanning electron microscopy including electron backscatter diffraction.

\section{Experimental}

\subsection{Materials}

Chemical compositions of the three investigated steel grades are listed in Table 1. Material A is a ferritic-pearlitic structural steel with $0.45 \mathrm{wt} .-\%$ carbon. Material $\mathrm{B}$ is an austenitic high temperature steel, with higher amounts of stabilising elements such as $\mathrm{Cr}, \mathrm{Ni}, \mathrm{Mo}$ and $\mathrm{Ti}$. Material $\mathrm{C}$ is a ferritic cast steel with high amounts of $\mathrm{Cr}$ and $\mathrm{C}$, which results in chromium carbide networks, which can increase wear resistance [5]. 
Table 1: Chemical composition of the materials investigated.

\begin{tabular}{|c|c|c|c|c|c|c|c|c|c|}
\cline { 3 - 11 } \multicolumn{1}{c|}{} & \multicolumn{8}{c|}{ Alloying elements [wt.-\%] } \\
\hline Affiliation & Material number & Fe & C & Si & Mn & Cr & Ni & Mo & Ti \\
\hline Material A & 1.1191 & bal. & 0.45 & 0.25 & 0.65 & - & - & - & - \\
\hline Material B & 1.4571 & bal. & 0.08 & - & 1.80 & 18.00 & 13.00 & 2.50 & 0.30 \\
\hline Material C & 1.4777 & bal. & 1.40 & 2.00 & 1.00 & 30.00 & - & 0.50 & - \\
\hline
\end{tabular}

\subsection{High temperature scratch test (HT-ST)}

The HT-ST is a newly developed tribometer for high temperature scratch and hardness testing $[2,10,11]$. The test rig mainly consists of a heated sample holder and a loading unit placed in a vacuum chamber (as seen in Figure 1). To prevent oxidation of the components, the indenter, samples and the resistance heated sample holder are kept under vacuum conditions. Actuators enable the sample positioning and the relative movement between indenter and samples' surface. The typical sample size is $70 \times 30 \times 15 \mathrm{~mm}$.

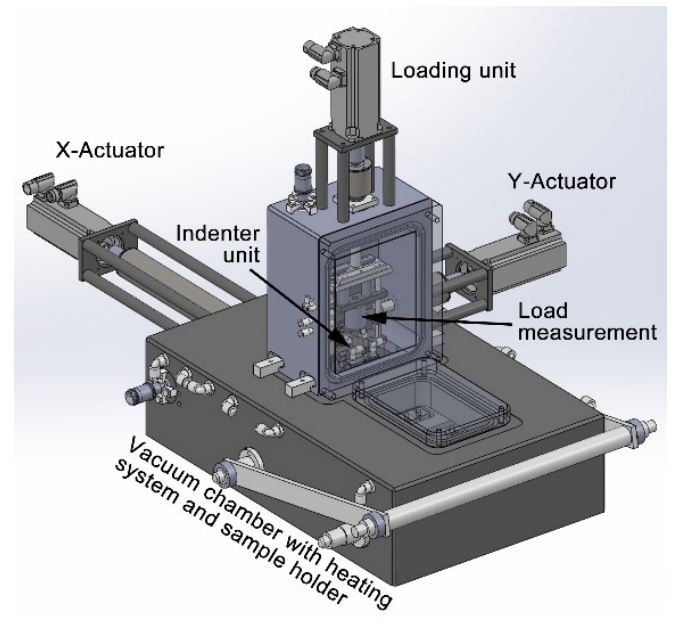

Figure 1: Overview on the high temperature scratch test $[2,6]$.

For optimal control of temperature and force, the whole scratching process is automatised. Normal forces can be adjusted up to $500 \mathrm{~N}$ by the loading unit. Sliding velocity can be up to $1 \mathrm{~mm} / \mathrm{s}$ in the X-direction and the temperature can be varied from room temperature to $1000^{\circ} \mathrm{C}$. Within this study tests were performed at $50 \mathrm{~N}$ normal load and room temperature (RT), $300^{\circ} \mathrm{C}, 500^{\circ} \mathrm{C}$ and $800^{\circ} \mathrm{C}$. To show the influence of the velocity, $10 \mathrm{~mm} / \mathrm{min}$ and $1 \mathrm{~mm} / \mathrm{s}$ were used at all temperatures. Also hot hardness measurements with Vickers-method and $10 \mathrm{~kg}$ load (HV10) were performed at several temperature levels (RT, 100, 300, $500,600,700,800^{\circ} \mathrm{C}$ ), revealing material hardness decrease due to thermal softening $[2,4,5]$. 


\subsection{Microscopy and analytics}

After the tests, all scratches were measured by means of a 3D laser confocal microscope (Leica ${ }^{\circledR}$ DCM 3D) to obtain the topography of the scratches and the penetration depth. Metallographic cross sections were prepared via sample cutting, embedding in plastic, grinding and polishing with $1 \mu \mathrm{m}$ grain size diamond paste. To reveal the microstructures all samples were etched (Material A: 3\% alcoholic nitric acid, Material B: V2A etchant, Material C: 3\% alcoholic picric acid). Different deformation mechanisms at the various phases present in steels were analysed with a light microscope (LM - Leica ${ }^{\circledR}$ MEF4) and a scanning electron microscope (SEM - Zeiss ${ }^{\circledR}$ Supra $\left.55 \mathrm{VP}\right)$. Material B was chosen for EBSD measurements (AMETEK ${ }^{\circledR}$ Pegasus) to gain deeper knowledge of the influence of temperature and scratching velocity on the strain hardening mechanisms of austenitic steels. EBSD-measurements were performed at the initial state and the deformed microstructural state at both velocities and $20^{\circ} \mathrm{C}$ and $500^{\circ} \mathrm{C}$. Areas of $30 \times 90 \mu \mathrm{m}$ with a step size of $100 \mathrm{~nm}$ were chosen for investigation. Tolerances were set to $5^{\circ}$ angle at a magnification of 3000 . The distance of the surface measuring the deformed microstructure was $2-3 \mu \mathrm{m}$ from the surface. Grain boundary images and inversed pole figures (IPF) were chosen for investigation, showing grain boundary changes and grain size variation. IPF (for these study in [100] orientation) pointed out eventual lattice orientation and texture changes.

\section{Results and discussion}

\subsection{Materials microstructural characterisation}

The different microstructures of all materials investigated can be found in Figure 2. Material A (Figure 2a)) shows ferritic-pearlitic microstructure with $\sim 55 \%$ pearlite and $45 \%$ ferrite. The RT-hardness of this steel is $195 \pm 3$ HV10. Material $\mathrm{B}$ shows austenitic microstructure with an average grain size of $40 \mu \mathrm{m}$ having a hardness of $172 \pm 2 \mathrm{HV} 10$ at RT. Material C reveals a ferritic matrix with a chromium carbide network around ferritic grain boundaries. The hardness is $420 \pm 5 \mathrm{HV} 10$ at RT.
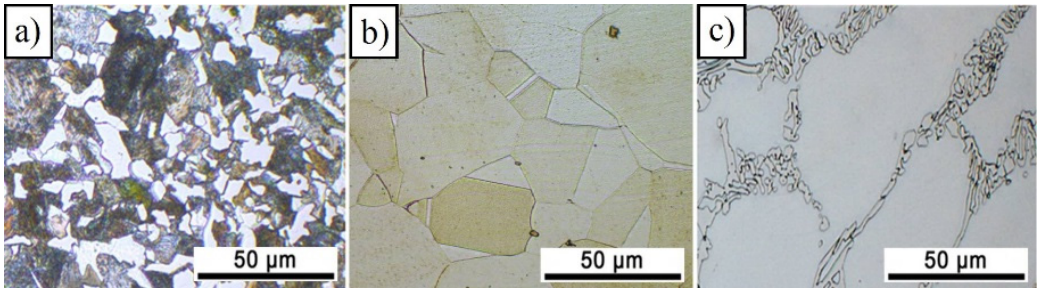

Figure 2: $\quad$ LM of microstructures: a) Material A - 1.1191, b) Material B 1.4571, c) Material C - 1.4777 . 


\subsection{Scratch depth versus hot hardness: quantitative analyses}

Hot hardness data of all materials investigated are given in Figure 3. The hardness of Material A decreases linearly up to $500^{\circ} \mathrm{C}$. Exceeding this temperature, the material is annealed and the hardness drops more rapidly.

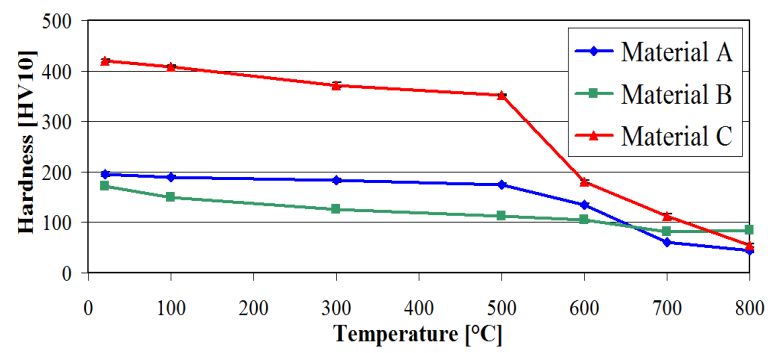

Figure 3: Hot hardness measurements of all materials.

Material B shows a linear decrease of hardness, due to higher amounts of $\mathrm{Cr}$ and $\mathrm{Ni}$ and austenitic microstructure. Material $\mathrm{C}$ reveals a linear hardness decrease up to $500^{\circ} \mathrm{C}$. After that the mechanical backup of the matrix to the carbides is lowered, which results in a rapid hardness decrease $[5,12]$.

An overview on scratch results is given in Figure 4. Already at first sight it can be pointed out, that the parameters material hardness, temperature and scratching velocity have a big influence on the scratch behaviour of materials.
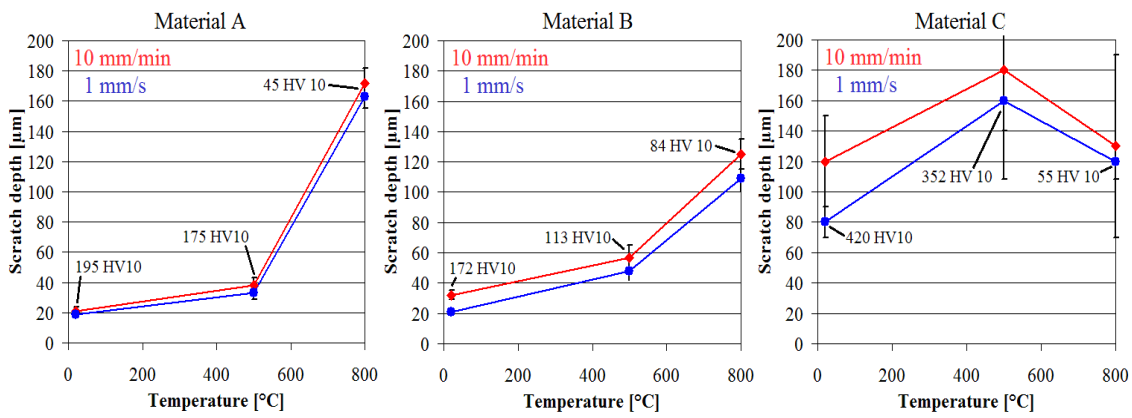

Figure 4: Quantitative results: scratch depth vs. hardness and temperature.

Material $A$ shows scratch depth inverse to its hardness decrease at elevated temperatures. Due to the high ductility the scatter of values is very small. It can be seen, that higher scratch depths were measured at elevated temperatures and decreased hardness, respectively. The influence of the velocity is small, but cannot be neglected. Deeper wear scars can be measured at lower velocity.

A similar, but clearer influence of velocity can be seen at Material $B$. The austenitic steel also shows increasing scratch depths with decreasing velocity. 
Also the temperature influences the scar depth - similar to Material A - inverse to the hardness decrease.

Different behaviour can be seen at Material $C$. The influence of the velocity is similar to the other materials, but at higher temperatures deep scratches can be measured, which have a large scatter. At the highest temperature of $800^{\circ} \mathrm{C}$ scratch depth decreases compared to $500^{\circ} \mathrm{C}$. The material tends to soften - the mechanical backup of the matrix decreases and the carbides are pressed into the matrix during the indentation [11]. At higher temperatures this effect is lowered, because the ferritic matrix shows higher ability to elastically deform.

It can be said, that the temperature and the resulting hardness have a huge influence on the scratch behaviour. For ductile and homogenous materials, such as $\mathrm{A}$ and $\mathrm{B}$, an inverse hardness correlation to the scratch depth is found, similar as in impact dominated systems [12]. For less ductile materials with hard phases, such as Material C, no coherence can be found at first. The explanation of this behaviour needs clarification with further methods.

The influence of both, temperature and velocity, on the scratch depths are pointed out in Box-and-Whisker-plots in Figure 5. The presented plots were constructed using the statistical programming language $\mathrm{R}$ [13] and show the median of all measured values (black line), their quantiles (box) and their scatter (whiskers). Further outlier can be easily detected.
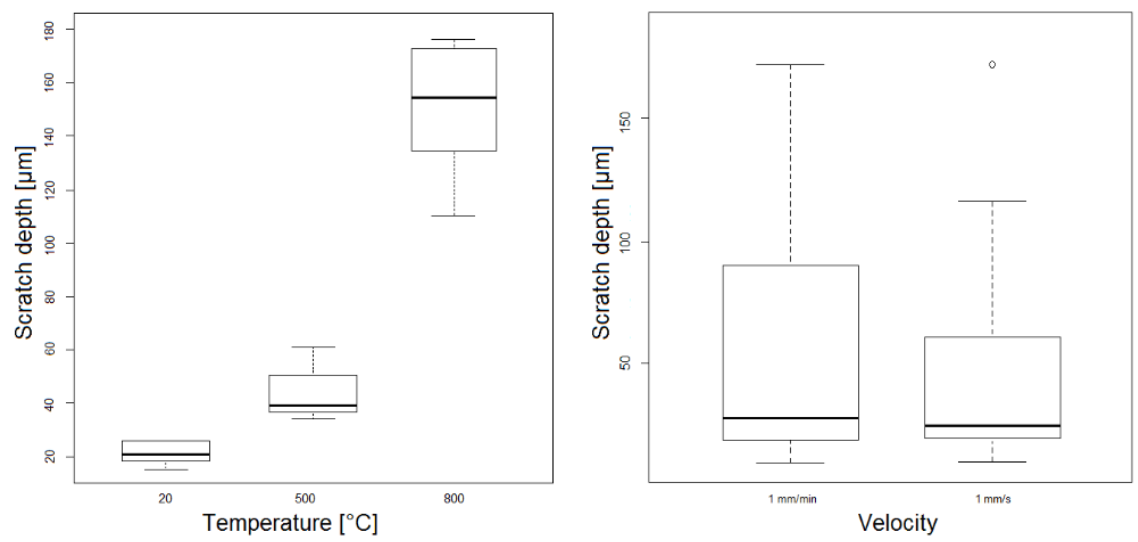

Figure 5: Box-and whisker-plots: Influence of temperature and velocity on the scratch depth.

Box-and-whisker-plots of the temperature-scratch behaviour were constructed for both velocities. Similarly the velocity-scratch depth-plots were constructed for all temperatures. Both plots merge the ductile materials (A and B), which reveal similar behaviour and similar hardness.

Compared to the influence of the temperature, the velocity influence is much smaller, but nevertheless wear scar depth can be increased up to $50 \%$ at lower velocities - materials tend to be more brittle at higher velocities resulting in 
lower deformation, caused by the motion of dislocations which is limited to a certain velocity. This causes strain hardening due to reduced dislocation motion, similar to strain rate effects within yield stress determination $[6,9,14]$.

The depth and the intensity of the hardness increase can be controlled with parameters like yielded deformation energy and the time span of deformation [9].

\subsection{Microscopical evaluations and micro hardness measurements}

The influence of temperature and velocity on the wear behaviour was investigated by different microscopical methods. Typical 3D topographies (area $1000 \times 1500 \mu \mathrm{m})$ at room temperature (RT) and $800^{\circ} \mathrm{C}$ and different velocities are given in Figure 6.

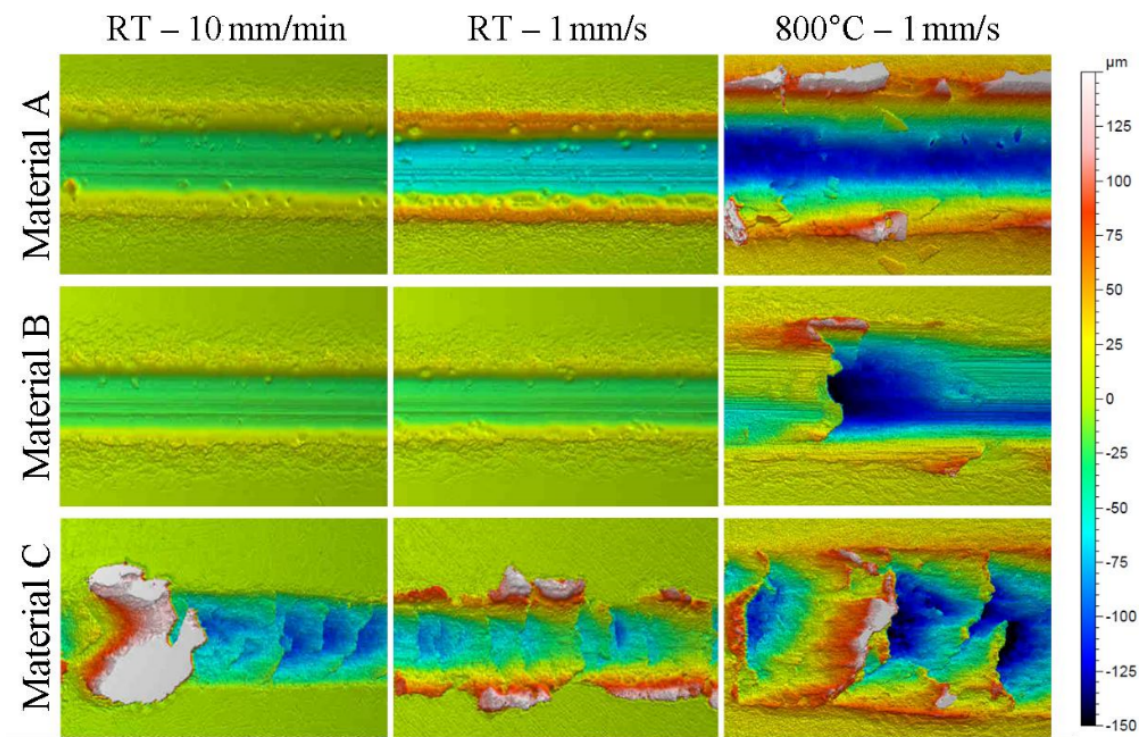

Figure 6: Scratch topographies (area $1000 \times 1500 \mu \mathrm{m}^{2}$ ), scratching direction from right to left.

At higher temperatures wider, deeper and most importantly more unstable scratches occur due to lowered hardness. Both ductile materials A and B show micro ploughing at low temperatures with some micro cutting at higher temperatures. But both materials show unstable scratch behaviour at $800^{\circ} \mathrm{C}$ with material overlapping and chipping - the temperature changes the wear mechanism. At high temperature micro cutting with small amounts of micro cracking can be observed.

Material $\mathrm{C}$ shows instable behaviour at all temperatures and velocities due to the irregularly distributed hard phases. At higher velocities more cracking and micro breaking can occur, which gets worse at higher temperatures, as visible in some loading cases at metal matrix composites and wear resistant cast irons [12, 14]. At higher temperatures, wear mechanisms are exacerbated - the deformation 
increases due to material softening; material transfer enhances more instable scratch behaviour and the wear reducing effect of carbides is decreased $[4,15]$.

Microstructural changes due to scratching can be seen within the cross sectional analyses in Figure 7. Different mechanisms occur at the microstructures. Material A shows different responses to scratching at both velocities. The influence at RT can be clearly seen. More densely packed and highly deformed structures are visible at high scratch velocities (higher strain rates), resulting in increased strain hardening of materials [cf. 14, 16].

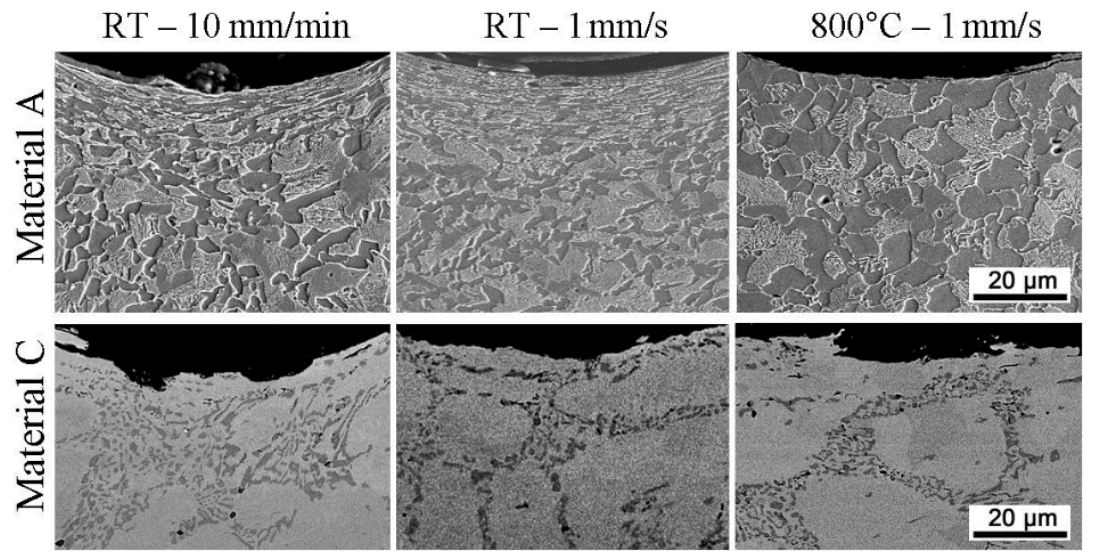

Figure 7: Metallographic cross sections of Material $\mathrm{A}$ and $\mathrm{C}$ at different temperatures and velocities.

The prior hardening mechanisms are grain refinement and the rearrangement and breaking of cementite which increases the hardness [9]. At the highest temperature a nearly initial-stated microstructure can be seen, due to the microstructural changes of carbon steels above $723^{\circ} \mathrm{C}$ and the concomitant recrystallisation [17].

Material $\mathrm{C}$ only reveals slight changes at varied scratch velocities; a more brittle behaviour is visible, and lower contents of ferrite within the surface zone, which can be put down to the wear resisting behaviour of the hard phases. More instable behaviour, maybe adhesive wear and displacement of carbides can be seen at elevated temperatures [18, 19], which was also pointed out in the 3D topographical analysis.

A detailed EBSD study on the deformation and hardening mechanisms of Material B is given in Figure 8. EBSD imaging was performed on the initial microstructure and directly under the scratch with low tolerances to enhance the quality of imaging. Grain boundary images and the corresponding [100]-oriented IPF are also given. As seen in the figure, different responses to velocity and temperature occur on the same material.

The undeformed microstructure reveals typical equiaxed grains with twin grain boundaries [20]. Grain sizes within this state range from 10-50 $\mu \mathrm{m}$; no preferential orientation within the grains can be detected in the IPF. 
The high velocity scratch $(1 \mathrm{~mm} / \mathrm{s})$ at $R T$ changes the microstructure significantly. High deformation up to $\sim 50 \mu \mathrm{m}$ with a high density of small angle grain boundaries (SAGB) and a high density of twin grain boundaries (TGB) can be detected. White areas indicate no Kikuchi pattern, which reflects a phase change, or poor sample preparation, but the high confidence index of all measurements suggests a phase change.

Previous studies indicate a martensite transformation $[9,20]$. IPFs indicate a high level of grain refinement and rearrangement to 101-orientation, which is common for fcc materials like austenites.
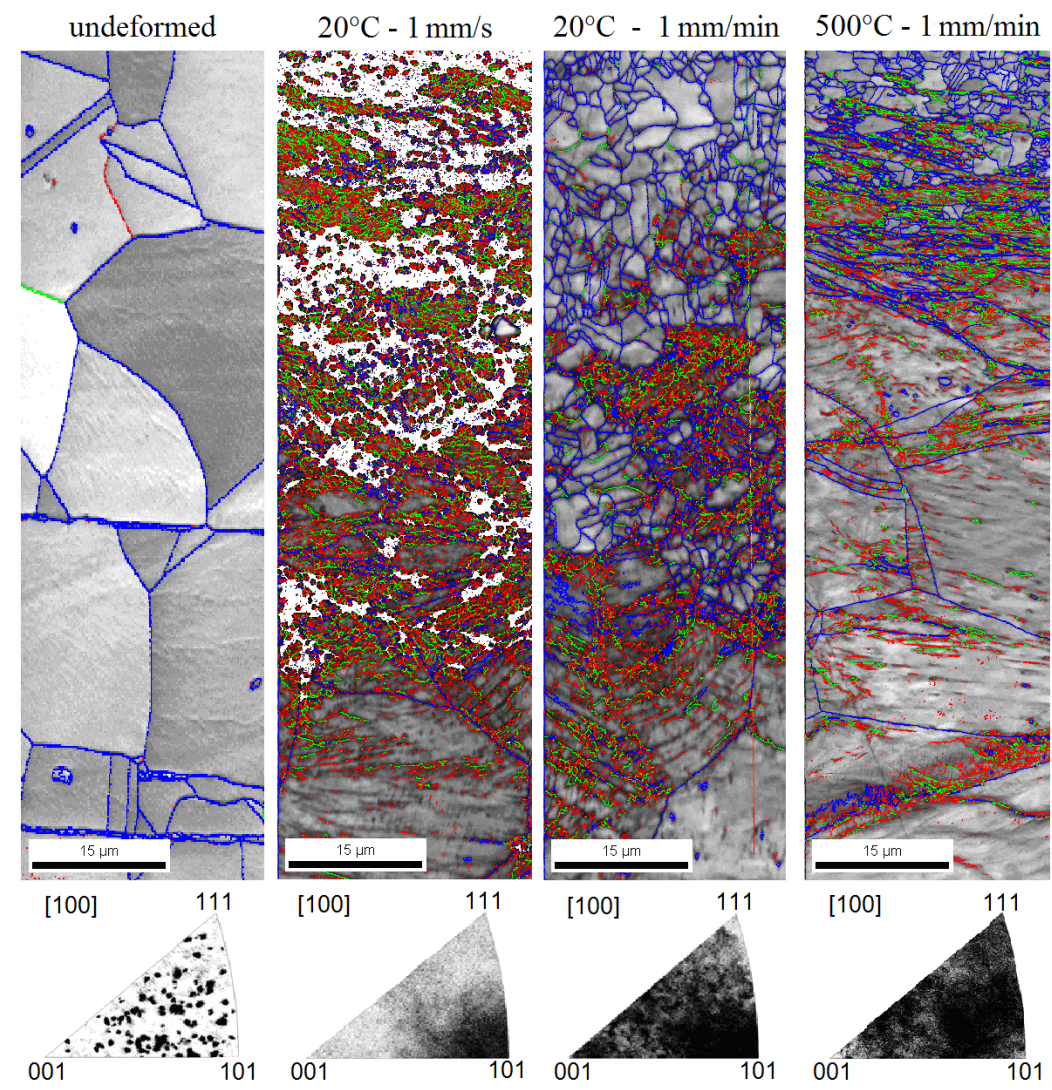

Figure 8: $\quad$ EBSD grain boundary images and inverse pole figures of austenitic Material B in the initial state and after scratch testing at different velocities and temperatures.

Higher velocities $(1 \mathrm{~mm} / \mathrm{s})$ at $R T$ tend to harden the material less. Lower amounts of SAGB and TGB can be seen; also rearrangement effects are visible. Dynamic recrystallisation, grain refinement and twinning are the main hardening 
mechanisms. Only grain refinement takes place on the surface near zones of the deformed zone

At slow velocities $(1 \mathrm{~mm} / \mathrm{min})$ and high temperature $\left(500^{\circ} \mathrm{C}\right)$ the temperature localises the dynamic recrystallisation closer to the surface $(\sim 20 \mu \mathrm{m})$. Grain rearrangements tend to be more random as seen in the IPF. Small angle grain boundaries are slightly more frequent than at the lower temperature, but are closer to the surface.

\section{Conclusion}

Within this study abrasive events were simulated via scratch testing up to $800^{\circ} \mathrm{C}$ at velocities of $1 \mathrm{~mm} / \mathrm{min}$ and $1 \mathrm{~mm} / \mathrm{s}$ on different iron based alloys. Based on the presented results following concluding remarks can be drawn:

- Temperature and velocity have a crucial influence on the wear resistance of the different iron based alloys investigated. In general temperature has a higher influence on the scratch depths, but also lower velocities can increase the scratch depth up to $50 \%$ at constant temperatures.

- The dominating wear mechanisms are micro ploughing and micro cutting for ductile steels (ferritic-pearlitic and austenitic steel). Inhomogeneous and more brittle materials (ferritic-chromium carbidic steel) enhance micro breaking and cracking.

- Ferritic-pearlitic steels mostly harden via grain refinement and cementite lamellae fracture. At high temperatures hardening mechanism decreases due to recrystallisation.

- Austenitic steels show grain refinement and rearrangement (also twinning) at all velocities and temperatures. High scratch velocities cause martensitic transformation, resulting in smaller wear scars.

- Ferritic-chromium carbidic steels show no significant hardening mechanism within the performed analyses. Higher temperatures cause increased ductile behaviour of the matrix which caused carbide displacement and cracking.

\section{Acknowledgements}

This work was funded by the "Austrian Comet-Program" (governmental funding program for pre-competitive research) via the Austrian Research Promotion Agency (FFG) and the TecNet Capital GmbH (Province of Lower Austria) and has been carried out within the "Austrian Center of Competence for Tribology" $\left(\mathrm{AC}^{2} \mathrm{~T}\right.$ research $\left.\mathrm{GmbH}\right)$. Authors are grateful to Mr. Philipp Eidenberger performing the EBSD measurements and to DI Grazyna Mozdzen (both AAC research $\mathrm{GmbH}$ ) for evaluating those measurements and intense discussion. Dr. Manel Rodriguez-Ripoll is acknowledged for intense discussion and his input. 


\section{References}

[1] Bhushan, B., Introduction to Tribology, John Wiley \& Sons Ltd: Chichester, pp. 1-6, 2013.

[2] Rojacz, H., Varga, M., Flasch, M., Badisch, E., Einfluss von Geschwindigkeit und Temperatur auf das Ritzverhalten von metallischen Werkstoffen und $\mathrm{MMCs}$ bis $1000^{\circ} \mathrm{C}$, Proc. Of the $14^{\text {th }}$ Internat. Metallography Conference Leoben, pp. 259-264, 2014.

[3] Zum Gahr, K.H., Microstructure and Wear of Materials, Elsevier: Amsterdam, pp. 80-123, 1987.

[4] Winkelmann, H., Varga, M., Badisch, E., Influence of secondary precipitations in Fe-based MMCs on high temperature wear behaviour, Tribology Letters 43, pp. 229-234, 2011.

[5] Varga, M., Rojacz, H., Winkelmann, H., Mayer H., Badisch, E., Wear reducing effects and temperature dependence of tribolayer formation in harsh environment. Tribology International, 65, pp. 190-199, 2013.

[6] Askeland, D., Wright, W., Essentials of Materials Science \& Engineering, Cengage Learning: Stamford, 2014.

[7] Lindross, M., Valtonen, K, Kemppainen, Laukkanen, A., Holmberg, K., Kuokalla, V.-T., Wear behaviour and work hardening of high strength steels in high stress abrasion, Wear 322, pp. 32-40, 2015.

[8] Ratia, V., Rojacz, H., Terva, J., Valtonen, K., Badisch, E., Kuokkala, V.T., Effect of multiple impacts on the deformation of wear resistant steels, Tribology Letters, accepted for publication, 2015.

[9] Rojacz, H., Mozdzen, G., Winkelmann, H., Deformation and strain hardening of different steels in impact dominated systems. Materials Characterization 90, pp. 151-163, 2014.

[10] Varga, M., Flasch, M., Paar, S., Badisch, E., Introduction of a novel tribometer especially designed for scratch-, adhesion- and hardness investigation up to $1000^{\circ} \mathrm{C}$, submitted to Proceedings of the Institution of Mechanical Engineers, Part J: Journal of Engineering Tribology.

[11] Varga, M., Stenszky, D., Badisch, E., Energy considerations of single abrasion phenomena at elevated temperatures via scratch method, Proc. of the $2^{\text {nd }}$ International conference of abrasive Processes, Cambridge, 2014.

[12] Rojacz, H., Hutterer, M., Winkelmann, H., High temperature single impact studies on material deformation and fracture behaviour of metal matrix compo-sites and steels. Materials Science and Engineering 562(A), pp. 39-45, 2013.

[13] R Development Core Team, $R$ : A language and environment for statistical computing, R Foundation for Statistical Computing: Vienna, 2008.

[14] Kocks, U.F., Strain Hardenening and Strain-Rate Hardening. Mechanical Testing for Deformation Model Development. ed. R.W. Rohde, J.C. Swearengen, ASTM International: West Conshohocken, 1982. 
[15] Rojacz, H., Varga, M., Kerber, H., Winkelmann, H., Processing and wear of cast MMCs with cemented carbide scrap, Journal of Materials Processing Technology, 214, pp. 1285-1292, 2014.

[16] Hertzberg, R.W., Vinci, R.P., Hertzberg, J.L., Deformation and Fracture Mechanics of Engineering Materials, John Wiley \& Sons: Hoboken, 2012.

[17] ASM International, ASM Handbook Volume 4: Heat treating, ASM International: Materials Park, 1991.

[18] Berns, H., Comparison of wear resistant MMC and white cast iron. Wear 254, pp. 47-54, 2003.

[19] Natarajan, N., Krishnaraj, V., Davim, J.P., Metal Matrix Composites, Springer: Berlin and New York, 2015.

[20] Marshall, P., Austenitic Stainless Steels - Microstructure and Mechanical Properties, Elsevier: Amsterdam, 1984. 